\title{
Diversity and Distribution of Bracket Fungi in Mt. Kilakiron, Bukidnon, Philippines
}

\author{
Mc Arthur L. Cababan*, Aprille Kaye O. Jaranilla, Mariane C. Bastatas, Chazzel Feel \\ C. Salvane, Uzziel C. Toldo
}

College of Education, Central Mindanao University, Philippines

*Corresponding Author: mcarthurcababan15@gmail.com

Submitted: 2020-04-16. Revised: 2020-12-14. Accepted: 2021-03-21

\begin{abstract}
Fungi have a lot of important function in the bionetwork resembling to decomposition and even nutrient cycling with respect to its symbiotic relationships with trees and other plants. This study aimed to assess the diversity and distribution of bracket fungi in Mt. Kilakiron, Portulin, Pangantucan, Bukidnon. Thus, floristic survey was conducted in one of the mountain of Mindanao to provide information as to what and how many species of bracket fungi are present in Mt. Kilakioron, Bukidnon, Philippines. 40 total species belonging to 17 genera and 5 family was collected and assessed. 12 individuals of Trametes versicolor were observe which favors dwellings with low temperature and high altitude are. Additionally, study revealed that most types of bracket fungi initiate in the site are decomposers and saprophytic in nature which contributes a lot in the process of putrefaction. The species of bracket fungi in Mt. Kilakiron clearly shows abundant and provides a large contribution to the ecosystem having high Shannon diversity index. The significance of each environmental factor is discussed in relationship to the ecology of the species. Bracket fungi are reliant on the climatic and conservational settings which makes them as excellent natural pointers of ecosystem in the forests of Mindanao Island, Philippines.
\end{abstract}

Key words: assessment; bracket fungi; distribution; diversity; morphology

How to Cite: Jaranilla, A. K. O., Bastatas, M. C., Salvane, C. F. C., \& Toldo, U. C. (2021). Diversity and Distribution of Bracket Fungi in Mt. Kilakiron, Bukidnon, Philippines. Biosaintifika: Journal of Biology \& Biology Education, 13(1), 41-50.

DOI: http://dx.doi.org/10.15294/biosaintifika.v13i1.24064

\section{INTRODUCTION}

The Island of Mindanao in the Philippines is known for its wide variety of endemic species of plants and animals. It is likewise recognized as one of the most naturally diverse islands in the country. Fungi are very diverse and large group of living organisms that can be found in nearly all ecosystem. It is estimated that there are 1,069 species of mushroom that have been reported as being used for food purposes worldwide (Boa, 2004). These wild edible mushrooms have been collected and consumed by people since thousands of years ago. Not only for food purposes, the bracket fungi can be used for the maintenance of health, as well as in the prevention and treatment of diseases. According to Wong and Cheung (2001), edible mushrooms contain a substantial amount of protein, fiber, vitamins, and minerals but low in fat. They also have various properties for health benefits and can be used to treat many human ailments such as cancer, circulatory system disorders and diabetes (Kim \& Song, 2014).They are mostly collected along forested areas. In addition, fungi love to grow on top of dead and decomposed leaves and logs.

Polypores are variable group of fungi may be morphologically, genetically, physiologically, and ecologically important. Most of the species are not closely related to each other that results very diverse group. It is a large group of fungi with over 30,000 species (Webster, 2007). In addition, it sustains its growth through decomposing dead and almost dying plant materials. Moreover, bracket fungi are distributed throughout the different area and can occur upon a variety of host species (Fogel \& Roger, 2006).

Indigenous knowledge results from many years of experience, it constitutes a connection between the community and their natural resources (Davies et. al., 2015). This research has been made in order to document and gather information for further studies in forthcoming. Therefore it will prevent both loss of traditional knowledge and its destructive changes during transmission between generations.

Mt Kilakiron is situated at an elevation of 2,329 meters above sea level. It is part of the Mt. Kalatungan Range that is the second largest mountain range in Bukidnon. It is known to be the boundary between the Municipality of Pangantucan and Valencia City, in the Province of Bukidnon. Mt. Kilakiron has an area approximately of $37,550.27$ hectares with its maximum elevation of 2,324 meters above sea level. It has the coordinates of latitude: $8^{\circ}$ $00^{\prime}-8^{\circ} 60^{\prime}$ and a longitude of between $124^{\circ} 35^{\prime}$ and $124^{\circ} 60$. The study area is surrounded with diverse flora and fauna species along with its numerous rivers 
and waterfalls, lakes, caves and rock formations that gives habitat to the different organisms (Naïve, 2017). This optimal condition of the province it very important to document its fungal diversity and because there is only a limited source of information regarding the macroscopic fungi, this research was conducted.

The exploitation of natural resources affects habitat quality by removing resources that are crucial for species as food, shelter or nesting sites. However, the realization of fragmentation effects may take decades (Hanski, 2013), particularly if there are still plenty of habitat in the landscape, habitat patches are large, and a species can tolerate moderate fragmentation (Rybicki and Hanski, 2013). This study aimed to assess the diversity and distribution of bracket fungi in Mt. Kilakiron, Portulin, Pangantucan, Bukidnon. They also have various properties for health benefits and can be used to treat many human ailments such as cancer, circulatory system disorders and diabetes (Kim \& Song, 2014) They also have various properties for health benefits and can be used to treat many human ailments such as cancer, circulatory system disor- ders and diabetes (Kim \& Song, 2014) They also have various properties for health benefits and can be used to treat many human ailments such as cancer, circulatory system disorders and diabetes (Kim \& Song, 2014)

\section{METHODS}

The study was conducted in Mt. Kilakiron, Portulin, Pangantucan, Bukidnon. Which is part of Mt. Kalatungan Range, the second largest mountain range in Bukidnon. It is known to be the boundary between the Municipality of Pangantucan and Valencia City, in the Province of Bukidnon. It has an area approximately of $37,550.27$ hectares with its maximum elevation of 2,824 meters above sea level. It has the coordinates of latitude: $8^{\circ} 00^{\prime}-8^{\circ} 60^{\prime}$ and a longitude of between $124^{\circ} 35^{\prime}$ and $124^{\circ} 60$. The study area is surrounded with diverse flora and fauna species along with its numerous rivers and waterfalls, lakes, caves and rock formations that gives habitat to the different organisms (Naïve, 2017).

Opportunistic sampling was done by the researchers. The species composition was observed during the study, and ecological characteristics of bracket fungi from the forest steppe of Mt. Kilakiron were studied. The characters of biotope, substrate type and its condition (wood species, alive or dead, and stage of wood destruction), and topic niche (living tree, standing dead trees, fallen trees, stub, strap, and root) were also registered when collecting fungi. A specimen that is an assembly of fruit bodies formed at the unit of wood substrate by one vegetative body of fungi was considered a registered unit. and Simpson's index of species richness, abundance and evenness was used in assessing bracket fungi species growing in Mt. Kilakiron (Dalisay, 2001).

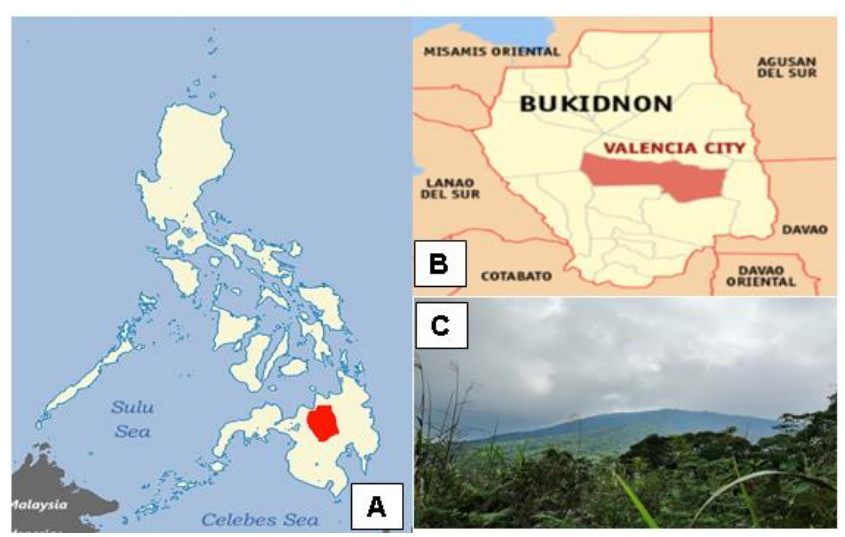

Figure 1. Study site. A) Map of the Philippines, B) Map of Bukidnon Province, C) Sampling site of M. Kilakiron

The study employed a transect walk method in collecting some of the bracket fungi. With an elevation up to $2,824 \mathrm{~m}$ above sea level, all specimens that were related on the study was collected and photographed. The needed data gathered during the sampling will be recorded on the field notebook.

The sample sites were according to different study sampling sites with its corresponding elevation. First was the Portulin proper to Intukas Peak or the Junction to Bonsai Garden with an elevation of 1,423 $-2,159$ meters above sea level. The Second sampling site was from Induyan Bonsai Garden to Baguic-ican River Camp Site with an elevation of 1,781-2,221 meters above sea level. Lastly, the Third sampling site was from Baguic-ican Falls to Tunaan Rest Area with an elevation of 1,732-1,805 meters above sea level. A global positioning system (GPS) was used to determine the location of the sampling sites.

The bracket fungi were gathered and recorded in the field notebook. Description of location site, ecological conditions and description of the bracket fungi were listed. All species that was seen in the transect walk was collected and were placed in the cellophane. It was photograph for further studies and identification.

The collected species were identified, classified and described morphologically with its fruit body specifically on its upper surface or the cap, on its lower surface, and if the collected species have stem or not based on the characters described in the Workbook in Tropical Fungi by Quimio (2001).

The following criteria were used to describe and identify the collected fungal specimens: (a) cap or 
pileus- size $(\mathrm{cm})$, shape, color and color changes (upper and lower surface), margin, and firmness of basidiocarp; (b) gills or lamellae-attachment to the stipe, thickness, forking, color and color changes, and orientation of hyphae in the inner gills; (c) stipe or stalk- size $(\mathrm{cm})$, diameter $(\mathrm{cm})$, attachment or position, shape, and firmness; (d) presence or absence of cystidia, basidia, and basidioles; (e) presence or absence of sterigmata; (f) mycelium-if visible, color when still attached to the basal stipe and the roots; (g) hyphae- relative size, presence or absence of septation and clamp connection and, (h) habitat (substrate) and edibility.

Identification was facilitated using standard dichotomous keys such asthose prepared by Arora (1986); Smith et al. (1988) and Hood (1992) together with colored and representative photographs from the books of Koon (1990), McKnight (1999), Quimio (1988 and 2001), and Laessoe (1998). Confirmation of initial identities of the specimens was further done by consulting with the expert from Central Mindanao University Museum.

The level of the distribution among the three-study sampling sites was done with the help of Biodiversity Professional or BioPro. Ver.2. The correlations analysis of the data was shown through a cladogram data and were evaluated among the study sampling sites.

\section{RESULTS AND DISCUSSION}

Results of the study revealed that with Mt. Kilakiron, Portulin, Bukidnon 40 species were known to occur which belongs to five families (Fomitopsidaceae, Ganodermaceae, Hymenichaetaceae, Polyporaceae and Stereaceae) and sixteen genera (Table 1). As shown in figure 1, the most diverse family in terms of number of genera genera was Polyporaceae with nine genera (56\%) and trametes as the most diverse genera with six total number of species (Figure 2) (Figure 3).

Table 1. Number of Bracket Fungi in Mt. Kilakiron, Bukidnon, Philippines

\begin{tabular}{llll}
\hline No. & Family & Genera & Species \\
\hline 1 & Fomitopsidaceae & 2 & 4 \\
2 & Ganodermaceae & 2 & 6 \\
3 & Hymenichaetaceae & 2 & 3 \\
4 & Polyporaceae & 9 & 21 \\
5 & Stereaceae & 1 & 4 \\
6 & Unidentified sp. 1 & & 1 \\
7 & Unidentified sp. 2 & & 1 \\
\hline Total & 5 & 16 & 40 \\
\hline
\end{tabular}

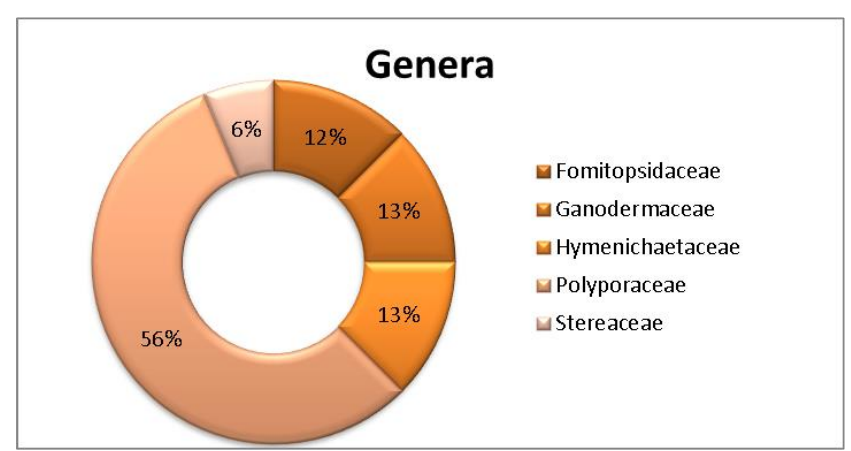

Figure 2. Dominant family in terms of Genera of Bracket Fungi in Mt. Kilakiron, Bukidnon

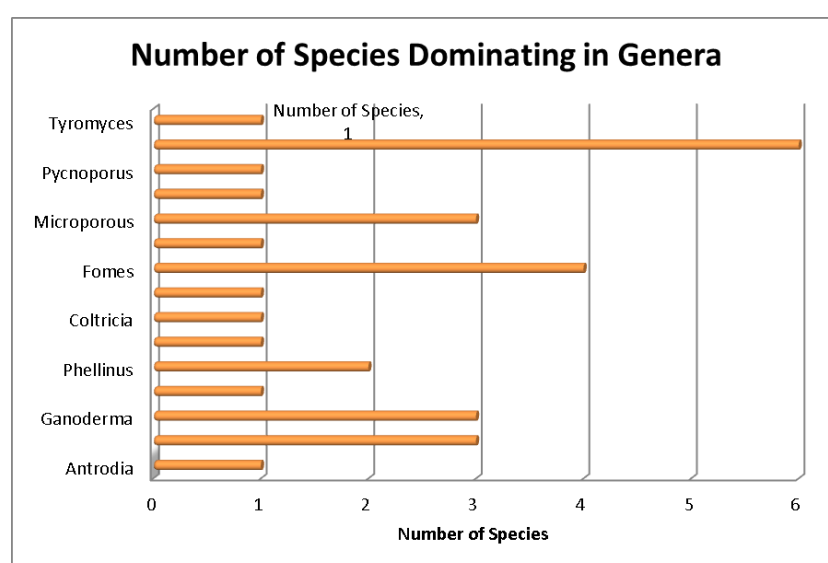

Figure 3. Dominant Genera in terms of Number of Species of Bracket Fungi in Mt. Kilakiron, Bukidnon

Fungi are an important part of the microbial ecology. The majority of fungi decompose the lignin and the hard-to-digest soil organic matter, but some fungi consume simple sugars. Fungi dominate in low $\mathrm{pH}$ or slightly acidic soils where soils tend to be undisturbed (Lavelle \& Spain, 2005). Fungi break down the organic residues so that many different types of microbes can start to decompose and process the residues into usable products.

Terrestrial species washed into aquatic habitats occasionally are collected and reported as aquatic. Among habitats, different taxonomic specialists may work at different ends of an ecotone and the same fungal species may be counted twice in the overall estimation of fungal diversity. For example, of the 405 miscellaneous mitosporic fungi reported from freshwater, 39 of the same species were reported from decaying wood in terrestrial habitats in a single geographical location (Wang, 2001). It is highly likely that species from aquatic habitats in the tropics also occur in the tropical rainforest habitat due to the very moist conditions. For example, Aliquandostipite khaoyaiensis was first described from a tropical rainforest (Inderbitzin et al., 2001) but later reported from submerged wood in the tropics (Raja et al., 2005). 
The varieties of production of mushrooms are mostly influenced by the temperature and precipitations. However, in woodlands the macrofungi that can be encountered all year round these are the bracket fungi and conk fungi. They are the kind of fungi that can be seen on the stems of deads or living tress. The presence and diversity of the bracket fungi have an important role as a dissociating factor of wood in the forest. The bracket fungi diversity can be different in stand and in fallen trees. The fungi, especially bracket fungi make three grade damages that include the fresh damaged, intermediate damaged and very damaged. The fungi abundance is more on rotted trees than on healthy trees (Rostamian, 2013).

Fungi have a lot of important function in the ecosystem. These may include decomposition, nutrient cycling, symbiotic relationships with trees and other plants (Caroll, 1997). For without fungi we the living being might be suffocated in piles of dead and dying biological matter that would not decay. The macro-fungi have very beautiful functions with the forest trees to take-up nutrients and water. It also gives protection to the tree roots from pathogenic fungi (Bratton, 2003).

Antrodia variiformis (Peck) Donk, Persoonia 4 (3): 340. Figure 5 (A). This fungus has a widespread distribution in study site. It appears thin and reddishbrown on its upper surface. While the lower surface has brown color. The species may grow in cluster or in a group on a dead tree and living tree trunk.

Fomitopsis cajanderi (P. Karst.) Kotl. \& Pouzar. Ceska. Mykologie 11 (3): 157 (1957). Figure 5 (B). The fruiting body is woody, annual or short-lived perennial and thick, that forms a fan-shaped and slightly convex. The upper surface of dark-brown in color with a whitish margin and an underside whitish brown. However, when it is a bit younger it has a pinkish-brown color.

Fomitopsis pinicola (Sw.) P. Karst. - Red-belted Bracket. Figure 5 (C). It has a classic red marginal belt that gives its common name, "Red-belted" polypore. This young species mainly has red-brown to blackish upper surface color. It has white lower surface but was covered with mud.

Fomitopsis spranguei (Berk. \& M. A. Curtis) Gilb. \& Pyvarden, Mycotaxon 22 (2): 364 (1985). Figure 5 (D). This semi-circular species has a fuzzy margin that has a brownish color. Has a width of 5.6 $\mathrm{cm}$ and length of $4.0 \mathrm{~cm}$. Its lower surface has grayish white color with angular pores.
Ganoderma applanatum (Pers.) Pat., Bulletin de la Societe Mycologique de France. 5: 67 (1889). Figure 5 (E). A very common perennial bracket fungus. It is mostly plain fan-like structure. It has a grayish-brown to black upper surface color along with its white or brownish ring edge. It has whitishbrown to black lower surface color.

Ganoderma australe (Fr.) Pat., Bulletin de la Societe Mycologique de France. 5: 71 (1889). Figure 5 (F). Its upper surface is brownish and uneven with pale margin. While, the lower surface is whitishbrown, and some are dark-brown in color. It is found near the base of the trees.

Ganoderma lucidum (Curtis) P. Karst. , Revue Mycologique Toulouse 3 (9): 17 (1881). Figure 5 (G.)

A young Ganoderma lucidum appears to have a reddish-brown color and white at the edges. Has a stem that is continuous with its fruitbody. A matured one appears to be varnished, reddish-brown, and fleshy upper surface. Its surface is roughly arranged into lumpy zones. At the lower surface, it is whitish with nearly invisible to the naked eyes circular pores.

Ganoderma tsugae var. jannieae Wasser, Zmitr. $\&$ M. Didukh, International Journal of medicine Mushrooms 8 (2): 171 (2006). Figure 5 (H). It is more-or-less fan-shaped fruitbody with shiny reddishbrown upper surface. While the lower surface has a dark-red color. The width is $15.8 \mathrm{~cm}$ and the length of $17 \mathrm{~cm}$.

Ganoderma sp. Figure 5 (I). Has a black upper body with brownish edges. Its lower surface has a whitish color. Found at a tree trunk.

Phellinus igniarius (L.) Quel., Enchiridion Fungorum in Europa media et praesertim in Galia Vigentum: 172 (1886). Figure 5 (J). It is mostly tough and woody texture. It has a brownish-black color of the upper surface, while its lower surface is in black color. Its width is $6.8 \mathrm{~cm}$ and a length of $5.5 \mathrm{~cm}$.

Phellinus sp. Figure $5(\mathrm{~K})$. It is tough that is brown in color of its upper body. The lower surface has grayish brown color.

Inonotus hispidus (Bull.) P. Karst., Meddelanden af Societas pro Fauna et Flora Fennica 5: 39 (1879). Figure 5 (L). It is a rusty yellowish-orange upper surface with semicircular and a rounded margin. Its lower surface has a creamy white color pore.

Coltricia perennis (L.) Murril, Journal of Mycology 9 (2): 91 (1903). Figure 5 (M). A shallow, thin-fleshed cap with an irregular margin. Has dark- 
reddish brown upper surface color. The back part has whitish-brown color. It has a width of $4.2 \mathrm{~cm}$ and a length of $3.7 \mathrm{~cm}$ with a stem of $3.2 \mathrm{~cm}$.

Daedalea quercina (L.) Pres., Synopsis methodica fungorum: 500 (1801). Figure $5(\mathrm{~N})$. It is a thickly maze-like pore lower surface that is brownish color. While it has a fan-shaped fruit body with its fuzzy whitish brown upper surface.

Fomes fasciatus (Sw.) Cooke, Grevillea 14: (69): 21 (1885). Figure $5(\mathrm{O})$. It has zonate fruitbody and an upper surface of light brown and zonate fruitbody color. The underside is in creamy white.

Fomes fomentarius (L.) Fr., Summa vegetabilium Scandinaviae 2: 237 (1849). Figure 5 (P). It is an annual layer of tubes build up to produce a large hoof-shaped structure. Has a dull, woody upper surface that is zoned with brownish gray color. The lower surface has a brownish color with an off-white margin.

Fomes hemitephrus (Berk.) Cooke, Grevillea 14 (69) 21 (1885). Figure 6 (A). Has a semi-circular fruitbody with brown and white upper surface. The underside has a creamy white color that has slightly visible pores. The width is $14 \mathrm{~cm}$ and a length of 12 $\mathrm{cm}$.

Fomes officinalis (Batsch) Kotl. \& Pouzar, Ceska Mykologie 11 (3): 158 (1957). Figure 6 (B). It has a hoof-shaped or columnar fruitbody. The upper body has a brownish gray in color. With its whitish brown lower surface and its margin.

Laetiporus sulphureus (Bull.) Murill, Mycologia 12 (1): 11 (1920). Figure 6 (C). A wavy-edged with soft and spongy fruitbody. With a cap's color of pale yellow-orange when it is moist. The lower surface has bright yellow-orange color.

Microporus affinis (Blume \& T. Nees) Kuntze, Revisio generum plantanum 3 (2): 494 (1898). Figure 6 (D). It varies on its upper surface color, may be black or brownish with its whitish edge. While its lower surface is creamy white in color. It also has stem or stalk that also varies in color depending on its fruitbody.

Microporus xanthopus (Fr.) Kutnze, Revision generum plantarum 3 (2): 494 (1898). Figure 6 (E). The fruiting body of the species have a funnel-shaped cap that is thin and smooth. The species was shaded in rings of brown and beige with a pale-yellow margin. The lower side has a creamy white color and was supported with its yellow-footed stem.

Microporus sp. 1 Figure 6 (F). The inner surface is reddish brown color having grayish white boarder or ring along the cup. While the lower surface has pale orange in color having visible pores. It has a stem with a brownish color.

Microporus sp. 2 Figure $6(\mathrm{G})$. The inner surface is pale brown color. While the lower surface has brownish in color having visible pores. With a width of $2 \mathrm{~cm}$ and a length of $1.5 \mathrm{~cm}$. It has a stem with a brownish color of a length of $1.7 \mathrm{~cm}$.

Microporus sp. 3 Figure $6(\mathrm{H})$. It has a light brown color with semi-circular wavy edge on its fruitbody. The lower surface appears with its clear tiny pores that is brownish in color.

Polyporus alveolaris (DC.) Bondartsev \& Singer, Annales Mycologici 39 (1): 58 (1941). Figure 6 (I). It is yellow to orangey and appears as semi-circular. It usually has a short and stubby lateral stem. The lower surface is yellowish-white, and the pores are diamond-like to honey combed in shape.

Pycnoporus cinnabarius (jacq.) Fr., Systema Mycologium 1: 371 (1821). Figure 6 (J). The whole fruit body is bright orange. The upper surface is rough and wrinkled whitish orange and its lower surface has an orange color.

Trametes cubensis (Mont.) Sacc., Sylloge Fungorum 9: 198 (1891). Figure 6 (K). It has an irregular shape of its fruitbody. Upper surface of young caps exhibits lumpy orange concentric cream zones. The lower surface is white in color.

Trametes hirsute (Wulfen) Pilat, Atlas Champ. Euur., Polypor., B: 265 (1939). Figure 6 (L). It features a semi-circular grayish, hairy upper surface. Its margin is often brownish and its pore surface. The lower surface is whitish in color.

Trametes ochracea (Pers.) Gilb. \& Ryvarden, North American Polypores 2: 752 (1987). Figure 6 (M). These is a semi-circular or shell shaped that is usually broadly attached to the substrate. The upper surface comprises concentric zones of various shades of brownish orange. While the underside is creamy white and is covered in mainly roundish pores. The pore surface does not stain significantly when it is bruised on tree trunk. 
Trametes versicolor f. nigrozonata (Bondartsev) Domanski, orlos \& Skirg., Flora Polska Grzyby (Mycota) 3: 222 (1967). Figure 6 (N). The upper surface is a fuzzy. It has a thin and do not get very big. About normal size are a couple of inches. There are obvious zones of color hues which most often are a shade of some brown with an off white outer margin in upper margin. There is also a black Trametes versicolor. Its lower surface has a creamy white color to brownish.

Trametes sp. 1 Figure $6(\mathrm{O})$. It has a concentric orange wavy in color that has thin fruit body. The lower surface appears to be in white.

Trametes sp. 2 Figure $6(\mathrm{P})$. It has wavy fruit body that has been distorted. The upper surface area has a brown color with its lower surface that is white in color.

Tyromyces sp. It has fruit body that is crust-like. The upper surface is mostly light brown color. The color of the lower surface is usually creamy white.

Stereum Ostrea (Blume \& T. Nees) Fr. Epicrisis Systematics Mycologici: 547 (1838). It has a slicedfunnel-shaped fruiting body. Its upper surface has a brownish shade and it has no stem. It's under surface is smooth with whitish brown color.
Stereum rugosum Pers., Neues Magazin fur die Botanik 1: 110 (1794). Its fruit body are slightly detached at the edge to the wood, when it was younger it resupinate and may form small woody brackets. The surface is smooth and has yellowish color. Has an underside of creamy-white color. When the surface is scraped, it produces blood-red marks. Accordingly, the species can be seen all throughout the year but shed spores on autumn.

Stereum striatum var. ochraceoflavum (Schwein.) A. I. Welden, Mycologia 63 (4): 797 (1971)

The body is silvery white with small silky fibers often fused and stalkless. Fertile surface is light buff that fades in age, smooth and wrinkled with white cylindrical spores.

Stereum sp. It has uneven fruitbody. The upper surface concentric brown with whitish edge. The lower surface has a brownish white circular spore.

Unidentified sp. 1. As what we have observed, the unidentified species has a brown color upper surface with uneven edges. The lower surface has brown spores.

Unidentified sp. 2. This figure appears thick and has brown-orange upper surface with an orange edge along the cap. It has an orange underside spores. 


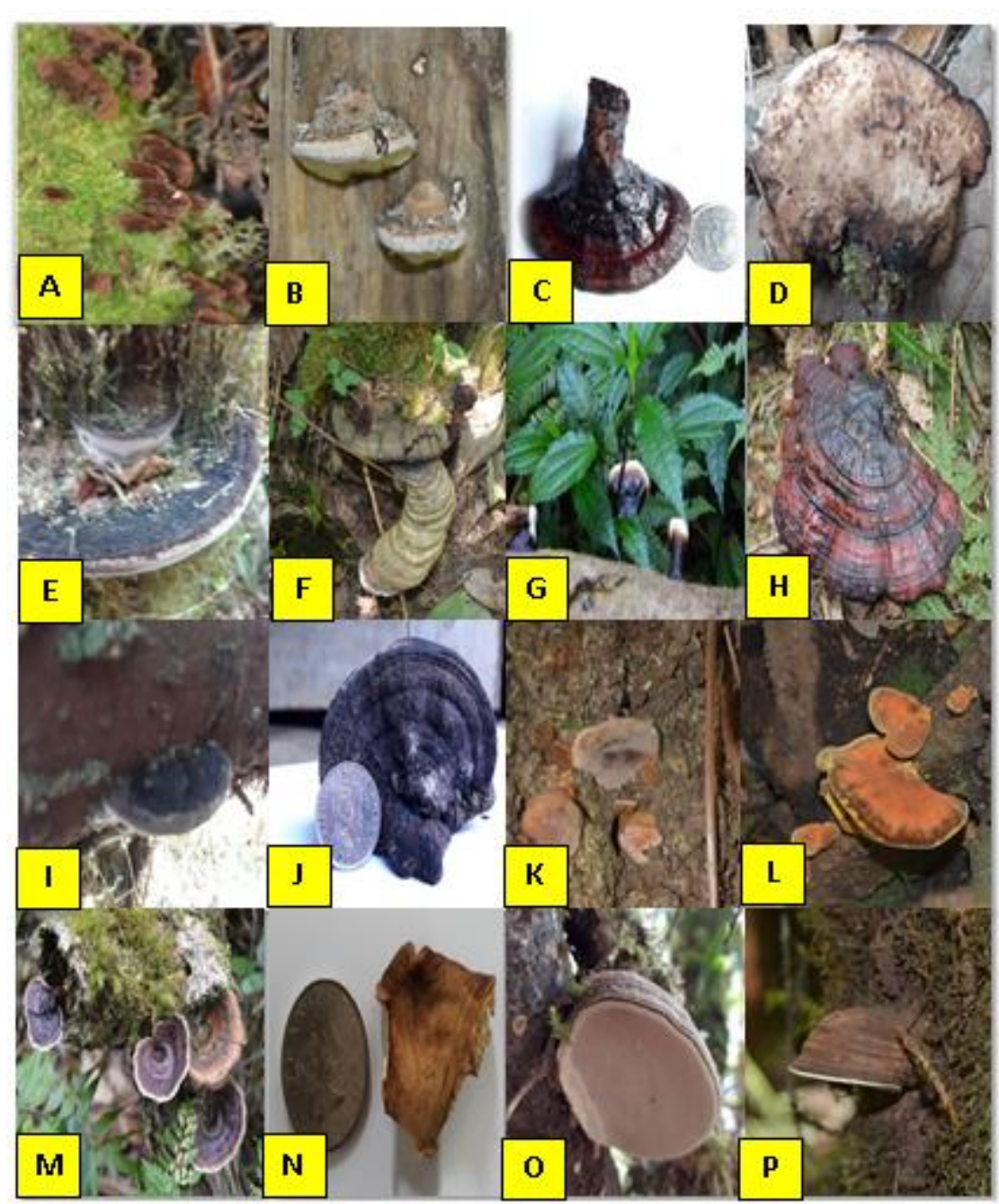

Figure 5. Selected Fungi Species. A. Antrodia variiformis (Peck) Donk B. Fomitopsis cajanderi (P. Karst.) C. Fomitopsis pinicola (Sw.) P. Karst. D. Fomitopsis spranguei (Berk. \& M. A. Curtis) E. Ganoderma applanatum (Pers.) F. Ganoderma australe (Fr.) Pat. G. Ganoderma lucidum (Curtis) P. Karst H. Ganoderma tsugae var. I. Ganoderma sp. J. Phellinus igniarius (L.) Quel K. Phellinus sp. L. Inonotus hispidus (Bull.) P. Karst M. Coltricia perennis (L.) Murril N. Daedalea quercina (L.) Pres O. Fomes fasciatus (Sw.) and P. Fomes fomentarius (L.) Fr.

The study revealed that most types of bracket fungi found in the site are decomposers and saprophytic in nature. It is highly observable that bracket fungi with its entire species, contributes a lot in the process of decomposition and nutrient cycling in the forest floor e.g. dead and living trees and logs. They purely help in the decomposition process that would highly benefit the ecosystem and not merely infecting trees. Moreover, by killing and decomposing trees, the root-rot polypores creates an opening in forest stands thus results to an increase in biodiversity of the forest stand. Decaying trees also provide shelter to animals (Ginns, 2017). The species of bracket fungi in Mt Kilakiron clearly shows abundant and provides a large contribution to the ecosystem.

The diversity of bracket fungi in the three-day transect walk sampling was compared as shown in Figure 1. Shannon-Wiener Index was used to show the evenness of diversity and abundance among the species. It shows that the Study Sampling Site 3 has the highest species diversity with a species diversity value of 1.259. It is then followed by the Study Sampling Site 2 of sampling in species diversity with a species diversity value of 1.199 . The Study Sampling Site 1 of sampling got the lowest diversity value of 1.125 .

Table 2. Species Diversity of Bracket Fungi in Mt. Kilakiron, Bukidnon.

\begin{tabular}{llllll}
\hline Index & & & Quadrat & Quadrat & Quadrat \\
& & & 1 & 3 \\
\hline $\begin{array}{l}\text { Shannon } \\
\text { Base 10. }\end{array}$ & H' $^{\prime}$ & Log & 1.125 & 1.199 & 1.259 \\
\hline
\end{tabular}

The results present in Mt. Kilakiron shows a high species diversity in Study Sampling Site 3 followed 
by Study Sampling Site 2 and Study Sampling Site 1, respectively. This implies that the study site is diverse with bracket fungi species shown in the result.

The results also implied that the difference in the bracket fungi composition of the said study sites were significantly different. Furthermore, the results may be attributed to the wider geographic ranges of bracket fungi and that certain species are typically restricted to more specific microhabitats, causing them to often have widely disjunct distribution patterns and are prone to localize extirpation (Shevock, 2001).

Table 3. Species Checklist and Distribution to three sites of Mt. Kilakiron, Bukidnon

\begin{tabular}{|c|c|c|c|c|}
\hline Species & Site A & Site B & Site $\mathrm{C}$ & No. of Site \\
\hline Antrodia variiformis (Peck) Donk & / & / & & 2 \\
\hline Fomitopsis cajanderi (P. Karst.) & I & & & 1 \\
\hline Fomitopsis pinicola (Sw.) P. Karst. & & l & & 1 \\
\hline Fomitopsis spranguei (Berk. \& M. A. Curtis) & & & l & 1 \\
\hline Ganoderma applanatum (Pers.) & I & & l & 2 \\
\hline Ganoderma australe (Fr.) Pat. & l & & l & 2 \\
\hline Ganoderma lucidum (Curtis) P. Karst & I & l & & 2 \\
\hline Ganoderma tsugae var. & & l & I & 2 \\
\hline Ganoderma sp. & / & & & 1 \\
\hline Phellinus igniarius (L.) Quel & l & I & & 2 \\
\hline Phellinus sp. & I & & & 1 \\
\hline Inonotus hispidus (Bull.) P. Karst & & I & & 1 \\
\hline Coltricia perennis (L.) Murril & I & & I & 2 \\
\hline Daedalea quercina (L.) Pres & & I & & 1 \\
\hline Fomes fasciatus (Sw.) & I & / & & 2 \\
\hline Fomes fomentarius (L.) Fr. & / & l & I & 3 \\
\hline Fomes hemitephrus (Berk.) & & & / & 1 \\
\hline Fomes officinalis (Batsch) & I & & & 1 \\
\hline Laetiporus sulphureus (Bull.) & / & I & / & 3 \\
\hline Microporus affinis (Blume \& T. Nees) & / & / & & 2 \\
\hline Microporus xanthopus (Fr.) & / & & / & 2 \\
\hline Microporus sp. 1 & / & & & 1 \\
\hline Microporus sp. 2 & l & & & 1 \\
\hline Microporus sp. 3 & & & / & 1 \\
\hline Polyporus alveolaris (DC.) & & & / & 1 \\
\hline Pycnoporus cinnabarius (jacq.) Fr & & / & & 1 \\
\hline Trametes cubensis (Mont.) & & & I & 1 \\
\hline Trametes hirsute (Wulfen) & & & I & 1 \\
\hline Trametes ochracea (Pers.) Gilb. \& Ryvarden & & & I & 1 \\
\hline Trametes versicolor $\mathrm{f}$. nigrozonata & I & I & I & 3 \\
\hline Trametes sp. 1 & I & l & & 2 \\
\hline Trametes sp. 2 & & & I & 1 \\
\hline Tyromyces sp. & & & I & 1 \\
\hline Stereum Ostrea (Blume \& T. Nees) Fr & & & I & 1 \\
\hline Stereum rugosum Pers., & & & I & 1 \\
\hline Stereum striatum var. & & & I & 1 \\
\hline Stereum sp. & & & l & 1 \\
\hline Unidentified sp. 1 & & & I & 1 \\
\hline Unidentified sp. 2 & & & I & 1 \\
\hline 40 & 19 & 14 & 23 & \\
\hline
\end{tabular}

Legend: / - Present

In gathering the entire species, transect-walk method was used. The presence of these species might be due to the high relative humidity of the site that ranges from $41.4 \%$ - 49.4\%. Another contributing factor could be the altitude, with the different ranges of the altitude the different species of bracket fungi were seen on the site. In the range from 1,423 - 2,159 meters above sea level there were thirty-three individuals that belonging to seventeen species seen from the first study sampling site. While, 
in the altitude of 1,781 - 2,221 meters above sea level there were twenty individuals, belonging to seventeen species also were seen from the second study sampling site. Lastly, in the altitude of 1,732 - 1,805 meters above sea level there were forty-four individuals that belongs to twenty-five species were seen from the third study sampling site. Other factors that might contribute to the distribution of bracket fungi are the abundance of logs, dead woods, and decaying materials found in the study area and with that (Santos, 1986) stated that there are some patches of closed areas wherein medium size residual tress grew raging from the altitude of $250-450$ meters above sea level.

The most common species of bracket fungi observed and recorded is the Trametes versicolor with twelve individuals that are found in both the low and high elevation of the study site. This kind of bracket fungi prefers in moist and cold places. The second most common species observed was Ganoderma applanatum with ten individuals, where some of the oldest and largest species observed. Which we believed that its spores were washed out by the rain causing them hard to distinguish, the same with the other Ganoderma species. However, the shape, structure, color, and thickness of the fruitbody of each species reveal its distinguishing differences and similarities. The Pycnoporus cinnabarinus species is a beautiful orange polypore that saprophytic on hardwoods, same as the other bracket fungi species. In Britain and Ireland, it was classed as endangered on their UK Red Data List. According to O'Reilly (2017), that this species might be a foray records on Europe but as observed in many countries it is very rare to be seen and should not be picked up.

The study revealed that most types of bracket fungi found in the site are decomposers and saprophytic in nature. It is highly observable that bracket fungi with its entire species, contributes a lot in the process of decomposition and nutrient cycling in the forest floor e.g. dead and living trees and logs. They purely help in the decomposition process that would highly benefit the ecosystem and not merely infecting trees. Moreover, by killing and decomposing trees, the root-rot polypore creates an opening in forest stands thus results to an increase in biodiversity of the forest stand. Decaying trees also provide shelter to animals (Ginns, 2017). The species of bracket fungi in Mt Kilakiron clearly shows abundant and provides a large contribution to the ecosystem.

\section{CONCLUSION}

The study assessed the distribution of bracket fungi in Mt. Kilakiron, Portulin, Pangantucan,
Bukidnon. There were 40 species of bracket fungi identified belonging to15genera. The genera Trametes has the most species with six species, followed by both the Ganoderma and Microporus with five species, then Fomes and Stereum with four species, Fomitopsis with three species, and Phellinus with two species. The species diversity was highest in Plot 3 with $\mathrm{H}=1.259$ followed by Plot with $\mathrm{H}=$ 1.199 and the least is Plot with $\mathrm{H}=1.125$. The study revealed that most types of bracket fungi found in the site are decomposers and saprophytic in nature.

\section{ACKNOWLEDGEMENT}

The researcher would like to express their most profound gratitude and appreciation to each and every one who helped the researcher in making this study successful. The researcher would also like to extend his wholehearted gratitude and respect to Central Mindanao University College of Education for the approval of this study. DENR, PAMB and LGU unit for the support. Barangay officials and Indigenous People group of Barangay Portulin for the provisions during the entire study duration.

\section{REFERENCES}

Boa, E.R. (2004). Wild edible fungi: a global overview of their use and importance to people (No. 17). Food \& Agriculture Org.

Bratton, J.H. (2003). Habitat Management to Conserve Fungi: a Literature Review. In http://www.bbsrc.ac.uk/waxcap/downloads/Bratto n-HabitatManagementFungi.pdf.

Caroll, J.E (1997). Fun with Fungi. In http:// commons.cornell.edu/bitstream/handle. 1813/9440/Fun\%20fundi.pdf?sequence $=2$.

Dalisay, T. U. (2001). Saprophytic Fungi. Workbook on Tropical Fungi: Collection, Isolation and Identification. The Mycological Society of the Philippines, Inc. pp 180-206

Fogel, R. \& Rogers, P. (2006). "Shelf fungi." Fun Facts About Fungi. Utah State University Intermoun-tain Herbarium. Available at: http://herbari-um.usu.edu/fungi/funfacts/shelf fungi.htm/

Ginns, J. (2017). Polypores of British Colombia (Fungi: Basidiomycota). FLNRO Technical Report 104.

Hanski, I., 2013. Extinction debt at different spatial scales. Anim. Conserv. 16, 12-13.

Inderbitzin P, Landvik S, Abdel-Wahab MA, Berbee ML (2001) Aliquandostipitaceae, a new family for two new tropical ascomytes with unusually wide hyphae and dimorphic ascomata. Am J Bot 88:53-61 
Iskandar, J., \& Iskandar, B.S. (2017). Various Plants of Traditional Rituals: Ethnobotanical Research Among The Baduy Community. Biosaintifika: Journal of Biology \& Biology Education, 9(1), 114-125.

Kim, H., \& Song, M.J. (2014). Analysis of traditional knowledge for wild edible mushrooms consumed by residents living in Jirisan Na-tional Park (Korea). Journal of ethnopharmacol-ogy, 153(1), 90-97

Lavelle, P. and Spain, A.V. (2005). Soil Ecology, Chapter 3: Soil Organisms, Springer: New Delhi, India.

McKnight KH. 1999. A Field Guide to Mushrooms of North America. USA

Quimio, T. H. (2001). Common Mushroom of Mt. Makiling, Museum of Natural History. University of the Philippines Los Banos, College, Laguna.

Quimio TH. 1988. Illustrated Philippine Fungi Techguide Series No. 24. National Bookstore. Mandaluyong, Philippines.
Santos, J. V. (1986). Guide of the Philippine Flora and Fauna: Natural Resources Management Center, Ministry of Natural Resource and the University of the Philippines. Volume IV, pp. 46135.

Webster, J. and Webster, R. (2007). Introduction to Fungi. In http://www.dbbe.feen.uba.ar/contenido/ objeto/WEBSTER30521807395.pdf.

Raja, Ferrer A, Shearer CA (2005) Alisquandostipite crystallinus, a new ascomycete species from submerged wood in fresh water habitats. Mmycotaxon 91:207-215

Rybicki, J., Hanski, I., 2013. Species area relationships and extinctions caused by habitat loss and fragmentation. Ecol. Lett. 16, 27-38.

Wang CJK (2OO1) Lignicolous hyphomycetes of New York: a preliminary report. Harvard Papers Bot 6:215-222

Wong, W.C. \& Cheung, P.C.K. (2001). Food and nutritional sciences programme. The Chinese University of Hong Kong, Shatin, New Territories, Hong Kong, China 